\title{
Information Management and Information System Analysis to Support the Achievement of University Performance Agreements with the Government
}

\author{
Titis Sari Putri* \\ Faculty of Computer Science \\ Brawijaya University \\ Veteran Road No.9 Malang, \\ Indonesia -65145 \\ titis.sari.putri@gmail.com
}

\author{
Herman Tolle \\ Faculty of Computer Science \\ Brawijaya University \\ Veteran Road No.9 Malang, \\ Indonesia -65145 \\ emang@ub.ac.id
}

\author{
Ismiarta Aknuranda \\ Faculty of Computer Science \\ Brawijaya University \\ Veteran Road No.9 Malang, \\ Indonesia -65145 \\ i.aknuranda@ub.ac.id
}

\begin{abstract}
The information management process and the use of information systems to support data collection and target achievements monitoring of rector's performance agreement with the Ministry of Education and Culture in Universitas Brawijaya (UB) still have deficiencies. The process involved many stakeholders and covered all areas of business at the university. As a work unit that collects and processes the performance achievement data, the Center for Quality Assurance UB complains that the information gathering takes a long time and is often incomplete. Faculties, study programs, and other work units complained about the unavailability of most of the data or information on the performance indicator targets in the information system used as a reference for implementing business processes. This problem received a general response from the UB ICT Unit that the information system developed and used is under academicians needs. Meanwhile, other academicians such as lecturers, employees, and students have different responses to problems. These problems are unclear and unstructured and have unpredictable goals and solutions. It is necessary to manage information by using reliable Information Systems by all work units to ensure the integration, availability, and validity of data for achieving performance targets. This study analyzed the problem and formulated a transformation step to improve the situation using the Soft Systems Methodology (SSM) with several Root Cause Analysis (RCA) stages. The research's main contribution provides an insight into the overall problem situation covering the various perspectives of stakeholders, the transformation of the state's improvement represented in the conceptual model, and stakeholder assessments of the conceptual model. This research also provides an overview of RCA's application to explore more stakeholder perspectives and identify building conceptual models.
\end{abstract}

Keywords: Soft Systems Methodology, SSM, Root Cause Analysis, RCA, University Performance Agreement

\footnotetext{
${ }^{*}$ Corresponding Author
} 


\section{Introduction}

State Universities have a performance agreement with the Ministry of Education and Culture (MoEc) called a university performance contract or rector's performance contract. It consists of performance indicators in the form of programs and targets to be achieved in a year (Kemenristekdikti 2016). To ensure the integration, availability, and data validity of performance targets achievement, information management by utilizing reliable Information System (IS) by all work units is needed.

Reliable IS is the capability of IS that enables the system to succeed (not fail) in achieving the intended objectives within a certain period and under a particular set of conditions (Zahedi 1987). To increase organizational competitiveness, IS needed to match the needs of business activities that refer to its plans and objectives (Almazán 2017). The use of IS following needs will impact improving the information management process, positively impacting productivity (Almazán 2017).

The process of collecting data and monitoring the performance targets' achievement on the rector's performance contract with the MoEC in Brawijaya University (UB) still has shortcomings. Collecting data of performance indicator targets from faculties throughout UB takes a long time and is often incomplete. Faculties, study programs, and other work units also complain about the unavailability of most of the data or information regarding the performance indicator targets in the operational information system. They have to carry out many steps to find valid information. Besides, many spreading data in several IS developed separately by the faculties, study programs, and work units make gathering information difficult. Many IS are not related to the IS used by many faculties and work units in UB so that the flow of information is not interconnected. That means that critical data needed by the university are not well absorbed in the university's IS. The problem received a general response from the UB ICT Unit that the information system developed and used follows the academicians' needs. In contrast, the information needed on performance targets is the leading information that reflects the university's general conditions and needs regular evaluation.

These problems are unclear, unstructured, have different perspectives from stakeholders, unpredicted goals, and solutions. Therefore, we need a concept of thinking that can accommodate the relationship between stakeholders by looking at problems as a whole and comprehensively, not in pieces, that called systems thinking. However, the case study in this research is not a technical problem with a clear problem definition and purpose that usually resolved by the concept of hard systems thinking, so that it has a different solution, namely using the concept of soft systems thinking.

Soft systems thinking is a way of thinking to accommodate messy problems, unknown objectives, what they want to achieve, and management elements (Checkland 1989). Based on the problem's description, the right approach that can guide researchers to analyze problem situations is the Soft Systems Methodology (SSM). SSM is an approach used to analyze, describe, and interpret problems from various stakeholders' points of view to develop a new conceptual idea needed to transform factual phenomena (Hardjosoekarto 2012).

Mehregan et al. (2012) and Por (2008) carried out the application of SSM in Higher Education to identify the problem in implementing scheduling and learning, where the results were structured and comprehensive conceptual modeling of problems and final solutions. Another form of SSM application is designing an evaluation framework for learning management environment using SSM principles carried out by Hardman and Caceres (2011).

This study aims to analyze and obtain transformation steps to improve the state of information management and use of information systems in achieving the target performance indicators for the rector with the MoEC in UB using SSM, with the addition of several stages of Root Cause Analysis (RCA). RCA is used to explore the root causes of problems and help develop conceptual models' activity in stage 4 of SSM. RCA is a methodology for finding fundamental problems and fixing performance problems, whether related to humans, systems, or equipment (Okes 2019). 


\section{Literature Review}

\section{Soft Systems Methodology (SSM)}

SSM consists of 7 stages as can be seen in Figure 1. The SSM model consists of two main activities: real-world activities seen in Stages 1, 2, 5, 6, and 7, and systemic activity thinking (systems thinking) seen in Stages 3 and 4. Not all stages of SSM should be followed when conducting research, depend on needs.

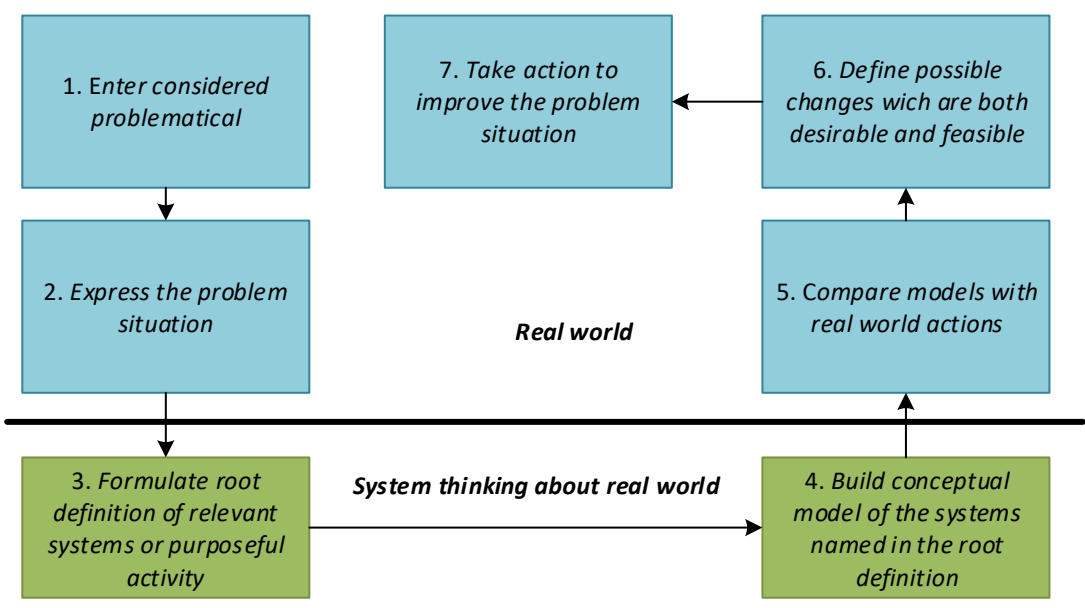

Figure 1. Soft Systems Methodology (Checkland 1989)

Stage (1) is enter considered problematical. This stage examines problems that are unstructured, complex, and have many perspectives (world views). Furthermore, stage (2) expresses the problem situation, namely describing the problem's complexity through a rich picture (s) to capture various perceptions related to the problem. Rich pictures are to be made as complete as possible to show the problem map, relations between actors, and views about the problem.

Stage (3) is formulating root definition of relevant systems or purposeful activity that means defining the root of the problems that includes particular views of the problematic situation by the relevant perspectives. This stage is supported by defining CATWOE (Customers, Actors, Transformation Process, Worldview, Owner, and Environmental Constraints). The customers are the parties who receive the benefits of the transformation process. In comparison, actors are the parties who can transform the situation based on the application of the conceptual model. The transformation process is an activity that shows the process of transformation, improvement, or optimization. Moreover, worldview is a paradigm that justifies the root definition. The owner is the decision-maker who has the responsibility of making the improvement efforts and stopping the transformation. Environmental Constraints are the elements outside the system that can become obstacles in the transformation process.

Stage (4) is building conceptual models of the systems named in the root definitions. The conceptual model is built as a transformation step to improve the situation. The input and output in the transformation process describe building the model. A comparison of the model with real-world conditions conducts in stage 5 by analyzing the possibilities of implementing the conceptual model activities.

Stage (6) is defining possible changes that are both desirable and feasible. This step conducts by assessing the results of interviews with the stakeholders about improvements or transformations to enhance the situation. It can be in the form of structures, procedures, or the attitude of the stakeholders. The next step in stage (7) is followed by improving the problem situation and implementing an action plan to carry out the transformation. 


\section{Root Cause Analysis (RCA)}

RCA is an approach to diagnose and solve problems that can enhance the process of corrective improvement in many organizations by discovering the underlying causes of problems (Okes 2019). The main objectives of RCA include (Rodriguez 2016): 1) identifying the root cause of the problem; 2) building general terminology in the corporate community to facilitate better communication and understanding; 3) learning from problems and failures.

There are many versions of the RCA stages, but, in general, they consist of the following steps: 1) identifying the problem, 2) making a diagnosis, 3) choosing and implementing a solution, and 4) improving and maintaining results. The diagnosis stages must be done logically with deductive analysis using critical thinking (Okes 2019). Figure 2 and Figure 3 show the RCA methodology used as a reference in this study.

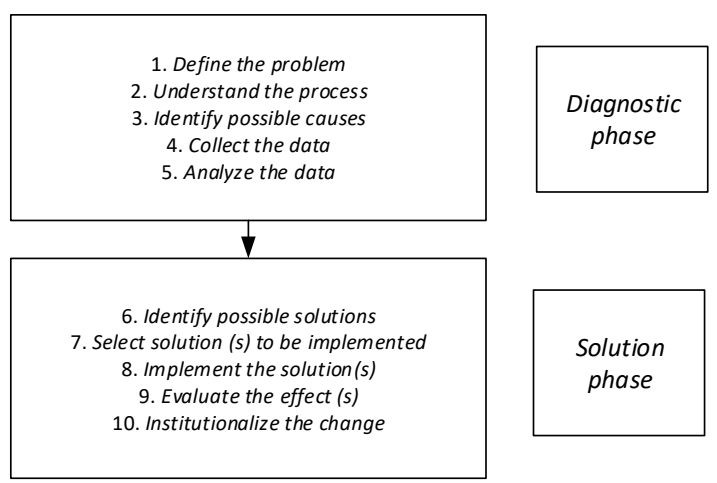

Figure 2. Root Cause Analysis (Okes 2019)

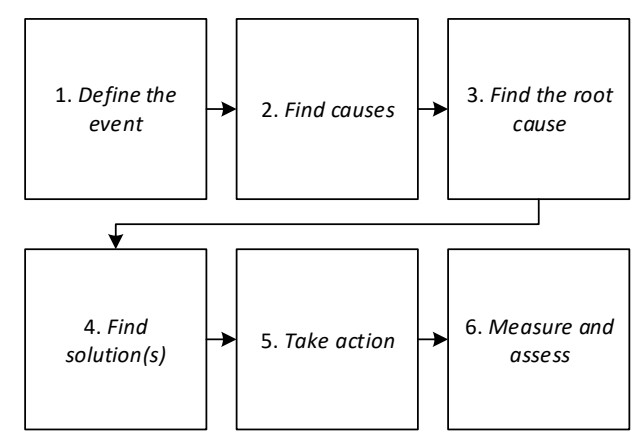

Figure 3. Root Cause Analysis (Andersen and Fagerhoug 2014)

The methodology proposed by Okes (2019) provides more detailed theoretical stages and explanations, while the methodology proposed by Andersen and Fagerhoug (2014) provides detailed practical guidance for RCA analysis and its tools. The two RCA methodologies will compare to ascertain, which of them was necessary, and several steps are selected to assist the analysis in SSM.

\section{Research Methodology}

The approach of this study is SSM, with the addition of several RCA stages. The RCA stages were analyzed by evaluating each stage's objectives and adding the stages to the results and objectives which were not in the SSM. However, the addition of the RCA stages to the SSM is not the main focus of this study. The research methodology is shown in Figure 4. The added RCA phases became parts of Stage 2 and 3, namely 2.1, 2.2., 2.3, and 3.1.

Since the early 2000s, there have been many SSM studies with several methods or techniques. These additions have varying complexity, ranging from the addition of specific techniques at the SSM stage 
to the development of new methodologies from the combination of SSM with other methodologies, such as the merging of SSM with System Dynamics (SD) by Ulloa and Careces (2005).

Ulloa and Careces (2005) and Hanafizadeh and Aliehyaei (2011) assume that the combination of SSM with other methodologies caused by the weakness of SSM. There are including 1) SSM does not have accurate tools to change the root definition at stage 3 to be the conceptual model in stage $4 ; 2$ ) The proposed conceptual model is considered based on certain viewpoints (not based on expert knowledge).

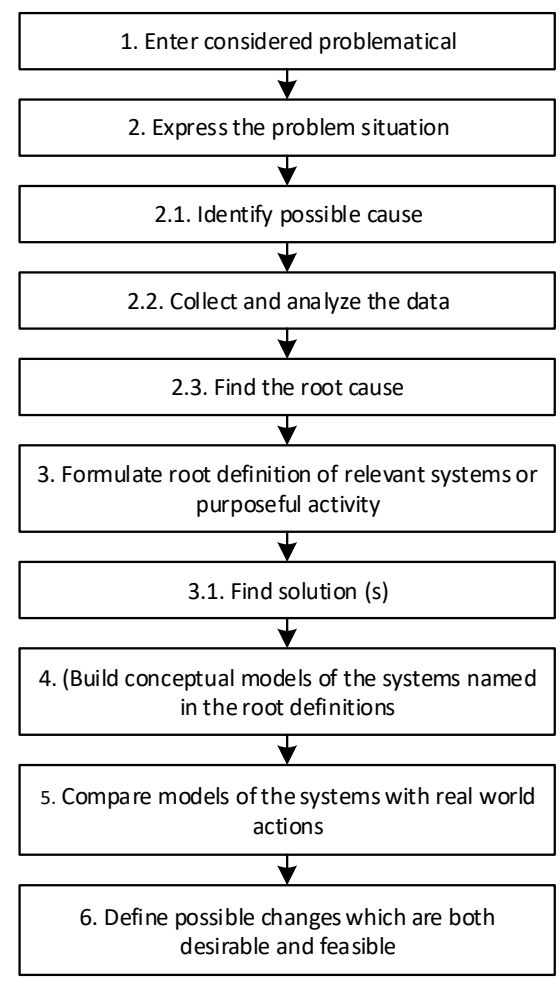

Figure 4. Research Methodology

Wheeler (2000) states that if SSM is a flexible methodology and not a fixed methodology. So it can be applied according to the user's motivation by not always following the seven stages. That statement comes from the constitutive rules of SSM developed by Checkland (1989) in the late 1980s. The rules for using SSM provide additional proof of SSM flexibility. The scope and flexibility of the application of SSM in various industrial fields, the ease of adding methods and other techniques to its stages, and the flexibility of combining with other methodologies show that SSM is developed with these objectives. Thus, using SSM with the added techniques or methodologies can be done flexibly depending on the needs and researchers or practitioners' creativity. Various techniques outside of SSM can overcome the presumption that SSM's deficiencies are related to the implementation process difficulties.

\section{Findings}

\section{Stage 1 and 2}

The rich picture in Figure 5 illustrates the problem situation described in the study's background. The description of the rich picture symbol is shown in Table 1 . 
Table 1. Description of the symbols in Rich Picture

\begin{tabular}{|l|l|}
\hline$\longrightarrow$ & $\begin{array}{l}\text { Description } \\
\text { Describe the direction of regulation and } \\
\text { information. }\end{array}$ \\
\hline & $\begin{array}{l}\text { Describe the direction of information flow, } \\
\text { information systems, and regulations. }\end{array}$ \\
\hline & Describe state or stakeholders' task. \\
\hline & Stakeholder complaints. \\
\hline
\end{tabular}

\section{Stage 2.1}

This stage identifies the possible causes of the problem by brainstorming the possible causes of the problem using a Cause and Effect Diagram (CED) or Fish-Bone Diagram, or the Ishikawa Diagram. The analysis begins by identifying the problems in stages 1 and 2 , then brainstorming the problems. Based on the initial analysis, the problem consists of three things, namely: 1) the lack of media availability to find information, 2) obstacles in gathering information, 3) obstacles in achieving performance targets. Figure 5 show the CED analysis of the lack of media availability to find information problem. At this stage, the causes of the problems were produced and would be explored more by using questionnaires and interviews at stage 2.2 , namely data collection and analysis.

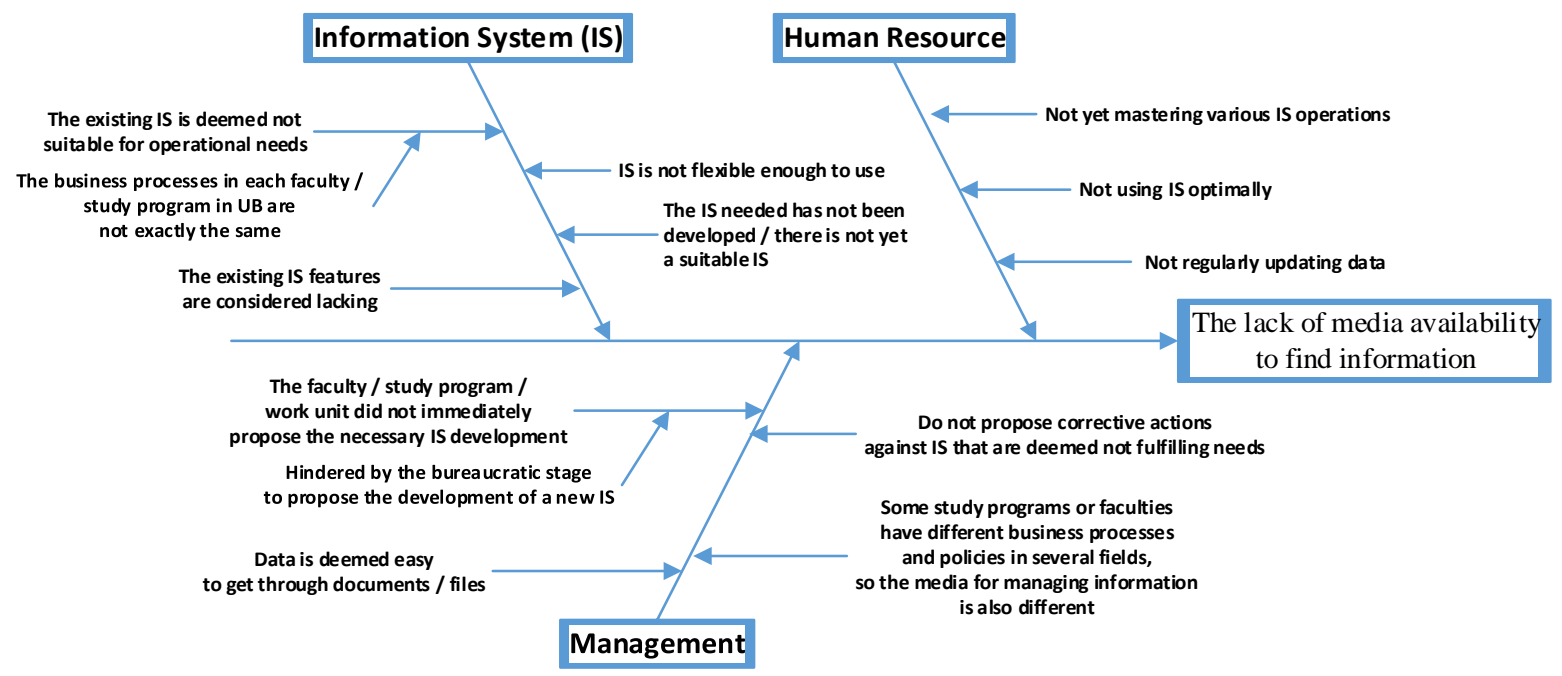

Figure 5. Cause and effect diagram analysis of the lack of media availability to find information

\section{Stage 2.2}

This stage gathers information, explore the causes of the problems, and confirm whether the brainstorming was already correct. Questions on the questionnaire and interview were following the brainstorming results by using CED. There are the media find information, obstacles in gathering information, and obstacles in achieving performance indicators. Identified the cause of the problems became the answer options in the questionnaire. Interview questions had the same question structure and choice of answers compared to the questionnaire, but they were used to gain more causes of the process's problems.

The questionnaire was carried out in Academic, Student Affairs, Staffing, Cooperation, Facilities, Infrastructure, and Research and Service units at each university faculty while interviews were conducted in 5 faculties. After obtaining the questionnaire results and interview on the faculty, an interview was conducted on the ICT unit to determine the ICT unit's perspective about the problem situation. 


\section{Stage 2.3}

Analysis in this stage is using the why-why diagram to find the root cause of the problem. The analysis is carried out following the categories of the causes of CED problems, for example, in the media's problems for information gathering. The causes of the problem are information systems, human resources, and management, where one why-why diagram analyses one category. From the complete analysis of why-why diagrams on each problem and each category, 26 root causes were found and categorized into four groups: the root causes of information system problems, human resources, management, and infrastructure (Figure 6). These root causes are shown in Table 2.
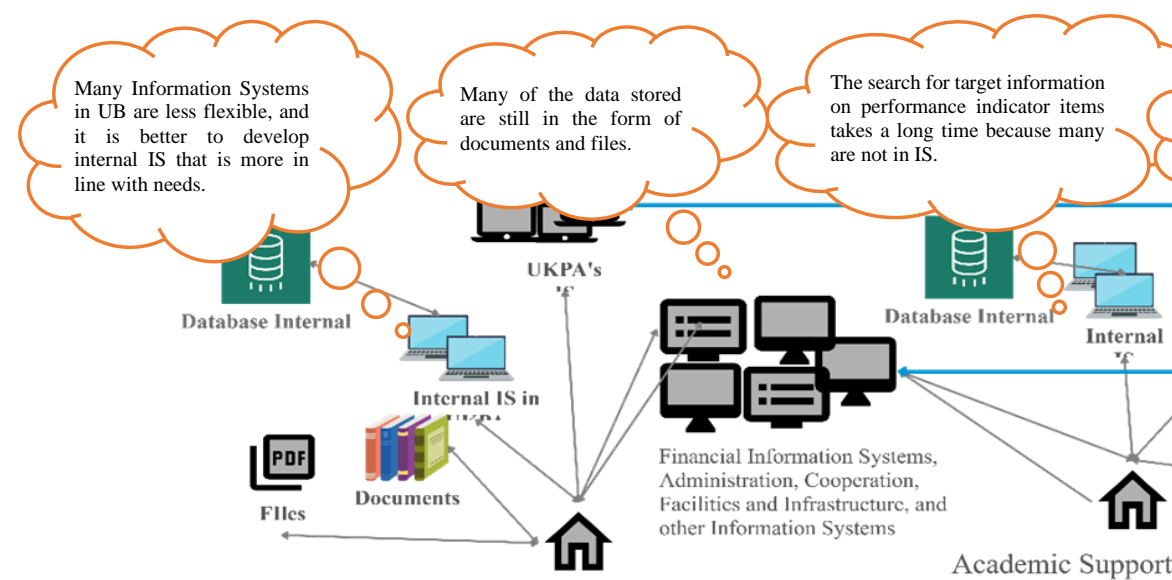

Academic Executive Work Unit

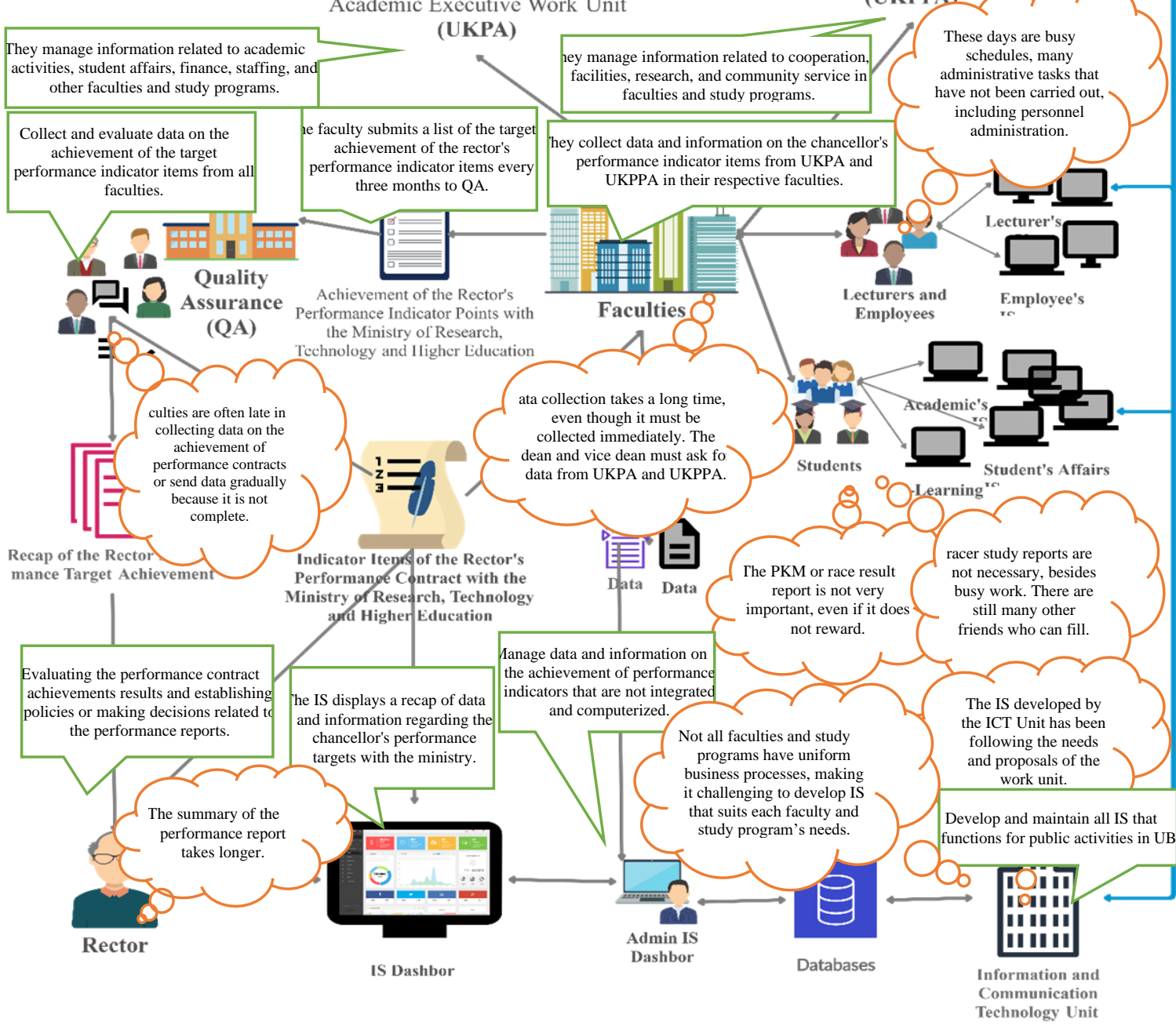

Figure 6. Rich picture 
Table 2. Root Cause

\begin{tabular}{|c|c|c|}
\hline No & Root Cause & Category \\
\hline 1 & Time constraints when developing information systems & \multirow{5}{*}{$\begin{array}{l}\text { Information } \\
\text { system }\end{array}$} \\
\hline 2 & $\begin{array}{l}\text { Deficiencies or errors in the development of information systems at the design } \\
\text { /coding stage }\end{array}$ & \\
\hline 3 & $\begin{array}{l}\text { Deficiencies at the requirements analysis stage of information system } \\
\text { development }\end{array}$ & \\
\hline 4 & $\begin{array}{l}\text { Number information systems, there are several overlapping information system } \\
\text { functions. }\end{array}$ & \\
\hline 5 & Shortages/errors when testing the information system. & \\
\hline 6 & Lack of information system development team. & \multirow{4}{*}{$\begin{array}{l}\text { Human } \\
\text { resource }\end{array}$} \\
\hline 7 & Lack of human resources to help manage information. & \\
\hline 8 & Employees need assistance and training in operational information systems. & \\
\hline 9 & Employees have many workloads. & \\
\hline 10 & $\begin{array}{l}\text { Each faculty has a type of educational program with various curricula so that } \\
\text { the business processes are different / not the same as other faculties. }\end{array}$ & \multirow{15}{*}{ Management } \\
\hline 11 & $\begin{array}{l}\text { The influence of internal campus policies and the development of government } \\
\text { regulations on business processes in each faculty. }\end{array}$ & \\
\hline 12 & $\begin{array}{l}\text { The administrative process long and complicated to propose improvements and } \\
\text { development of new information systems. }\end{array}$ & \\
\hline 13 & $\begin{array}{l}\text { Many information system developments internally to avoid the bureaucratic } \\
\text { process. }\end{array}$ & \\
\hline 14 & $\begin{array}{l}\text { Management of information (availability, regularity, and unity of information) } \\
\text { has not been a priority of the faculty. }\end{array}$ & \\
\hline 15 & Lack of faculty commitment to managing information well, & \\
\hline 16 & The government aims to unite data and information nationally & \\
\hline 17 & $\begin{array}{l}\text { The development of the university (its effect on increasing the workload of } \\
\text { employees to manage information) }\end{array}$ & \\
\hline 18 & $\begin{array}{l}\text { Differences in policies and regulations in each faculty (influence on business } \\
\text { processes and information management) }\end{array}$ & \\
\hline 19 & $\begin{array}{l}\text { Lack of commitment from the leadership to provide an understanding of the } \\
\text { achievements of university performance (to employees) }\end{array}$ & \\
\hline 20 & $\begin{array}{l}\text { Lack of leaders' commitment to understanding the importance of information } \\
\text { management (to all university stakeholders). }\end{array}$ & \\
\hline 21 & $\begin{array}{l}\text { Influence of university and government regulations and policies related to } \\
\text { educational staff competencies (related to performance indicators of } \\
\text { educational staff competencies) }\end{array}$ & \\
\hline 22 & Faculty priorities do not include some performance indicators. & \\
\hline 23 & The collaboration program is not a top priority for the faculty. & \\
\hline 24 & The influence of faculty/university leadership policies on funding & \\
\hline 25 & There is no information system to manage uncomputerized data. & \multirow{2}{*}{ Facility } \\
\hline 26 & UB has many data connected to many information systems. & \\
\hline
\end{tabular}




\section{Stage 3}

The formulation of the root definition in this study is carried out based on the perspective of the problem situation in general from the CED analysis results, questionnaires, interviews, and finding the root of the problem. The root definition in this study is as follows:

"Supports for the availability, quality, and unity of the performance indicators achievement data of the rector and the Ministry of Education and Culture can be improved by having good information management using

information systems according to the needs. It is possible to achieve this with the leader's commitment to improve information management and develop information systems, followed by stakeholder understanding of the importance of achieving performance indicators of the rectors with the Ministry of Education and Culture to represent university performance."

Based on the root definition above, the CATWOE analysis is shown in Table 3.

Table 3. CATWOE analysis

\begin{tabular}{|c|c|}
\hline CATWOE & Descriptions \\
\hline Customers $(C)$ & $\begin{array}{l}\text { Leaders (rector, vice-rector, dean, and other leaders), QA, UKPA (faculties and } \\
\text { study programs), UKPPA }\end{array}$ \\
\hline $\operatorname{Actors}(A)$ & All academicians at the university (lecturers, employees, students) \\
\hline $\begin{array}{l}\text { Transformation } \\
\text { process }(T)\end{array}$ & $\begin{array}{l}\text { - Improve information management processes and information systems to } \\
\text { ensure the availability and integrity of data } \\
\text { - Improve university management, both resources, and leadership policies } \\
\text { - Increase the fulfillment of the necessary facilities and infrastructure }\end{array}$ \\
\hline Worldview $(W)$ & $\begin{array}{l}\text { The achievement of the rector's performance indicator targets with the Ministry } \\
\text { of Education and Culture supports the improvement of university quality, which } \\
\text { must be achieved and improved }\end{array}$ \\
\hline Owner $(O)$ & Rector, QA, ICT unit \\
\hline $\begin{array}{l}\text { Environmental } \\
\text { constraints }(E)\end{array}$ & Government policies or regulations, university resources \\
\hline \multicolumn{2}{|r|}{ 3E Criteria } \\
\hline Efficacy & $\begin{array}{l}\text { The commitment of the top leaders and the entire academic community to carry } \\
\text { out the transformation }\end{array}$ \\
\hline Efficiency & $\begin{array}{l}\text { The collaboration of the transformation process with various work units } \\
\text { according to the problem domain }\end{array}$ \\
\hline Effectiveness & $\begin{array}{l}\text { Improve the process of managing information on the performance indicators of } \\
\text { the chancellor and the Ministry of Education and Culture by improving } \\
\text { information systems, business processes, information architecture, and data } \\
\text { integration }\end{array}$ \\
\hline
\end{tabular}

\section{Stage 3.1}

At this stage, identifying a possible solution of 26 root causes of the problem was identified. Writing down corrective and anticipatory actions from each root cause of the problem conduct to identify the solutions. Corrective and anticipatory actions at this stage helped define the elements of activities in developing conceptual models.

\section{Stage 7}

At stage 7, a conceptual model is built, contains nine activities as a state transformation step, shown in Figure 7. The first activity in the conceptual model is the initiation of FGDs and forming an evaluation team. This activity needs to conduct first because the problem is broad in scope, occurs in various fields, 
and involves many stakeholders. The second activity is to evaluate the information management process. Evaluating information management included all activities either they used the information systems or not. At this activity, an evaluation report is generated along with the preparation for starting the next steps.

The difference in information management business in several faculties was a significant problem that needed an immediate solution. Therefore, the third activity needed to be carried out immediately after the evaluation study. FGDs are conducted to find solutions to the differences in business processes and Standard Operational Procedures (SOP) for information management in each faculty. This activity produces the uniformity of information management business processes, agreements, and solutions.

After the FGD study results on business process uniformity, the next steps are Stages 5, 6, and 7, namely the integration of the university's data warehouse with external databases and improvement and development of information systems. These stages involve the Information and Communication Technology (ICT) unit's role at both the university and faculty levels.

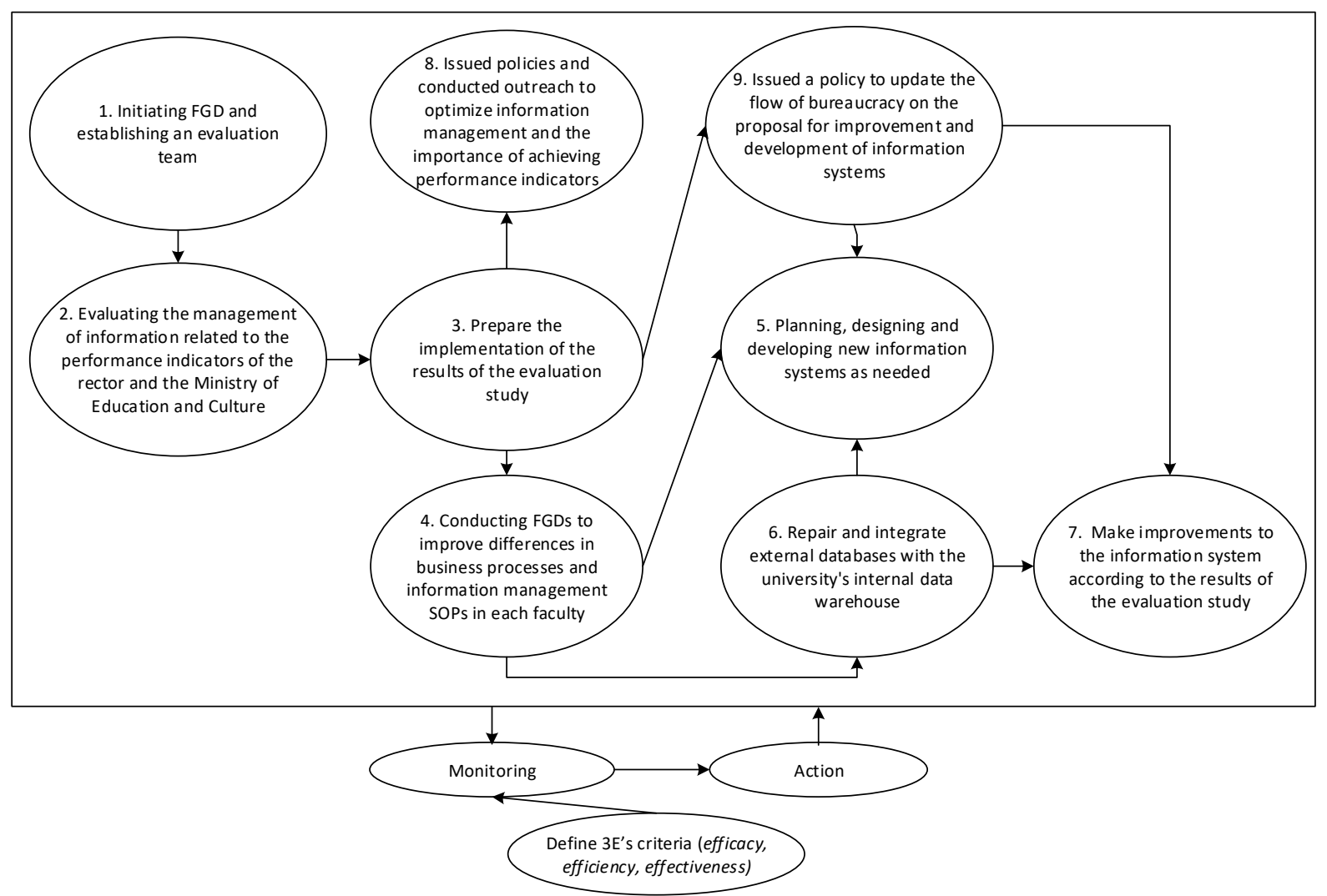

Figure 7. Conceptual Model

The next step is to optimize information management and achieve performance contracts. Optimization of information management arranges through several policies requiring lecturers and students to report various data, update routine employee data on facilities and infrastructure. Meanwhile, optimizing performance contracts' achievement includes enhancing faculty policies to prioritize the performance indicators achievement. This policy needs following by the stakeholders (employees, lecturers, and students).

\section{Stage 5 and 6}

At stage 5, the conceptual model is compared with real-world conditions to determine whether the conceptual model's activities can apply. The conceptual model is compared with the assumptions if the activities are implemented. Based on the comparisons at this stage, the results show that all conceptual models' activities can be applied. 
At stage 6, an evaluation arranges using a questionnaire to assess whether the proposed conceptual model's activities are appropriate and possible to be applied. The questionnaire is distributed to nine respondents, lecturers, employees, and leaders in the UB Quality Assurance Center. Each respondent's answer to the questionnaire was assessed qualitatively, where the respondent answered by choosing one of the five answers for each question. The quantitative answer scores substitute for qualitative by giving points to the selected answers in the data tabulation. The interval criteria are as follows: 1) Very Good $=4.21-5 ; 2)$ Good $=3.41-4.20 ; 3)$ Enough $=2.61-3.40 ; 4)$ Bad $=1.81-2.60$; and 5) Very Bad = $1.00-1.80$.

The provisions of the evaluation variables in the SSM conceptual model refer to Checkland's (1989) statement; that determines the possibility of organizational change based on logical and acceptable criteria from organizational culture. Referring to Checkland's (1989) statement, the evaluation variables consist of accuracy, resources, time, culture or habits, and motivation.

Based on the index method calculation, most of the conceptual model activities have a "Very Good" value, with an index value above 4.20. Others had a "Good" result with a score above 3.41. It shows that respondents approve and judge most activities in the conceptual model can be implemented. The graph of each activity's evaluation results based on the questionnaire results shown in Figure 8.

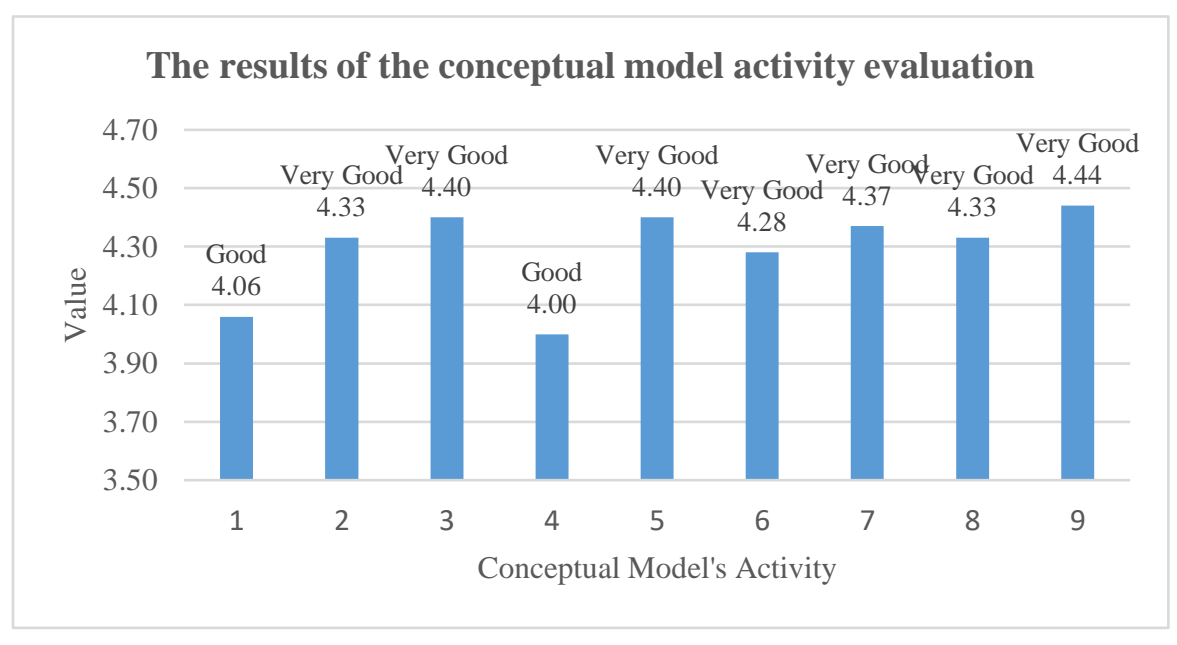

Figure 8. The evaluation result of each activity in the conceptual model

The activities assessment results in the conceptual model based on evaluation variables were mostly rated "Very Good." The graph of the index calculation results shown in Figure 9.

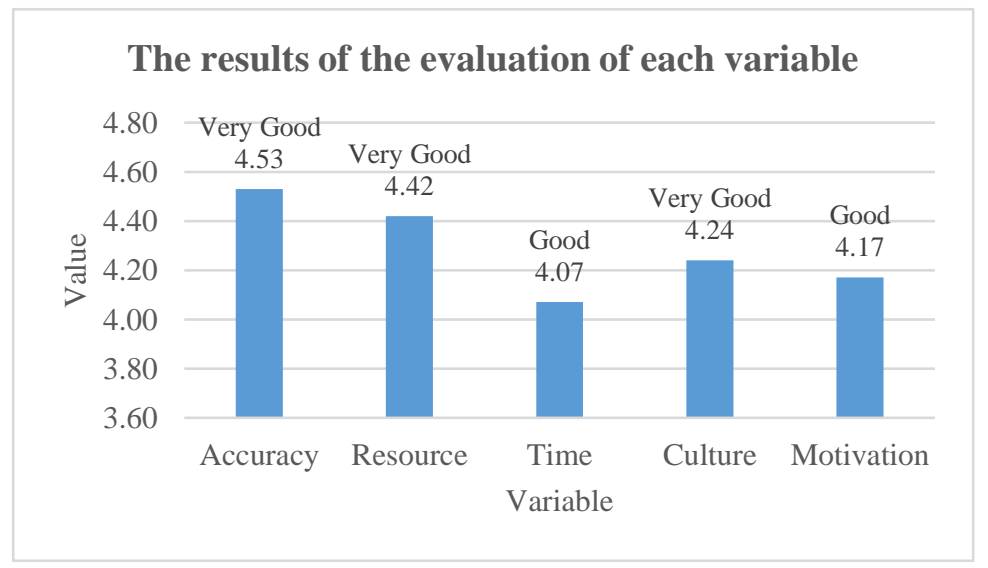

Figure 9. Result of the activities assessment based on evaluation variables 
The assessment of activities in the conceptual model in Figure 8 shows that the respondents assess all conceptual model activities as relatively appropriate and can be applied well. Figure 9 also shows that the conceptual model can be implemented because it fulfills the available resources, such as time, cost, culture, and motivation.

\section{Discussion}

The 12 problem perspectives were found from the rich picture in Figure 6 in the cloud-shaped dialog box. Apart from that, two other perspectives are implicitly seen in the picture, and there are problems with the policies and the influence of human resources on the information management process.

The 26 root causes of the problem are also another perspective of the problem. The RCA stage added to the SSM stage 2 successfully helps analyze the problem situation to get more perspectives than what is seen through the rich picture. With more perspectives that have been obtained, the broader the researcher will understand the problem situation.

The RCA stage added in stage 3 of SSM, namely identifying possible solutions to root causes, succeeded in helping researchers as a reference tool other than root definition in defining the activity elements in the conceptual model. Identifying corrective and anticipatory actions as possible solutions can also minimize differences in interpretation between different analysts in developing a conceptual model. However, the root cause analysis stage using the Why-why diagram in stage 2 can produce different root causes of problems depending on the researcher's ability and insight. Therefore, various parties that are considered to have ideas and knowledge to solve problems are essential.

The transformational steps for improving the situation are represented in a conceptual model consisting of 9 activities. These activities transform the overall state, including issues of information systems, human resources, management, facilities, and infrastructure. Each activity in the conceptual model can be developed by building subactivity to become more detailed, and technical steps for its application are determined to guide the university in improving the situation.

In stage 4, Checkland (1989) states that different researchers or analysts can develop different conceptual models from the same root definition because words give different connotations to each person. Checkland (1989) adds that the built model is not a model that is considered 'correct' but a coherent model and can be maintained. The suitability of the conceptual model built is assessed based on the evaluation by stakeholders. In Figure 8 and Figure 9, the conceptual model generally scores "good" and allows it to be applied.

Although SSM provides knowledge and produces conceptual models that are judged appropriate to problem situations, the discussion of the success of SSM has become a debate among researchers and SSM practitioners (Connel 2001). Several researchers have debated the measurement of the success of SSM, such as Mingers and Taylor (1992), Ledington and Donaldson (1997), and Kreher (1994). Connell (2001) proposed criteria for measuring the success of SSM, based on the aspects of the methodological contribution and evaluation of research results. The SSM success criteria divided into four quadrants as follows: 1) Q1 when SSM can be considered successful if it succeeds in providing insight; 2) Q2 when SSM can be considered successful if it helps manage/change management; 3) Q3 when the problem situation can be resolved through a clear understanding through understanding the use of SSM; 4) Q4 the problem situation has been successfully resolved, and changes can be managed through the use of SSM.

This research succeeded in providing insight into the structure of the problem, stakeholders' various perspectives, the transformation of the expected state, and the stakeholders' assessment of steps in the conceptual models. This understanding shows that the SSM approach succeeds in providing insight and includes success in the Q1 criteria. Simultaneously, the criteria for the contribution of the study's final results show that the activities in the conceptual model are acceptable and can be applied by stakeholders. In this case, the success of the research results is in Q3. 


\section{Conclusion}

This study analyzes information management's problem situation and information systems in achieving performance indicators for the rector and the Ministry of Education and Culture. The addition of three stages of RCA to SSM succeeded in finding 38 problem perspectives, namely 12 from the rich picture in stage 2 of SSM, and 26 from the RCA analysis. The root causes of the problems found are used for analysis by formulating the root definition and anticipatory and corrective actions. This analysis facilitates developing a conceptual model to determine what activities are required to transform problematic states. The conceptual model must also be tested to determine whether it is possible to apply it in the real world. The stakeholders' evaluation results indicate that the conceptual model in this study is acceptable and possible to apply. The results of the analysis of all stages provide insight and understanding of problem situations.

The contributions of this study include: 1) providing an overview of the application of RCA to explore problem perspectives that cannot be captured from the rich picture, 2) providing an overview of the use of the RCA approach to help develop conceptual models by defining corrective and anticipatory actions from the root causes of problems, 3 ) The research results can be used as input for initial research to evaluate the problems of information management and the use of information systems in Universitas Brawijaya.

This study's main limitation is the stakeholders' lack of involvement, especially in Stages 3, 4, and 5, due to the researchers' limited opportunities and time. Moreover, the RCA methodology's addition does not become one of the main discussions in the study because it focuses on exploring and understanding the problem situation.

Further research opportunities, this research can be developed on a broader research object, namely at many higher education institutions. The research results can be used as evaluation and learning materials regarding information management and reliable information systems to support higher education institutions' achievement in a performance agreement with the Ministry of Education and Culture.

\section{References}

Almazán, D. A, Tovar, Y. S, and Quintero, J. M. M. 2017. "Influence of information systems on organizational results," Contaduría y Administración (62:2), pp. 321-338.

Andersen, B., and Fagerhaug, T. N. 2014. The ASQ Pocket Guide to Root Cause Analysis. Milwaukee, USA: ASQ Quality Press.

Checkland, P.B. 1989. "Soft Systems Methodology”. Human Systems Management (8), pp. 273-289.

Connell, N. A. D. 2001. "Evaluating soft OR: Some reflections on an apparently 'unsuccessful' implementation using a soft systems methodology (SSM) based approach". Journal of the Operational Research Society, (52:2), pp.150-160 (doi: 10.1057/palgrave.jors.2601054).

Hanafizadeh, P., and Aliehyaei, R. 2011. "The Application of Fuzzy Cognitive Map in Soft System Methodology”. Systemic Practice and Action Research (24:4), pp.325-354 (doi: 10.1007/s11213011-9190-z).

Hardman, J., and Caceres, A. P. 2011. "A Soft Systems Methodology (SSM) Based Framework for Evaluating Managed Learning Environments". Systemic Practice and Action Research (24:2), pp. 165-185 (doi: 10.1007/s11213-010-9182-4).

Hardjosoekarto, S. 2012. "Construction of Social Development Index as a Theoretical Research Practice in Action Research by Using Soft Systems Methodology". Systemic Practice and Action Research (25:6), pp. 493-509.

Kemenristekdikti, 2016. "Peraturan Menteri Riset, Teknologi, dan Pendidikan Tinggi Republik Indonesia Nomor 51 Tahun 2016". Kemenristekdikti, pp. 1-58 (https://ittama.ristekbrin.go.id/wpcontent/uploads/2015/11/SALINAN-PERMENRISTEKDIKTI-NOMOR-51-TAHUN-2016TENTANG-SAKIP.pdf). 
Kreher, H. 1994. "Some recurring themes in using SSM". Journal of the Operational Research Society (45), pp. 1293-1303 (doi: 10.1057/jors.1994.202).

Ledington, P., and Donaldson, J. 1997. "Soft OR and management practice: a study of the adoption and use of Soft Systems Methodology". Journal of the Operational Research Society (48), pp. 229-240 (doi: 10.1057/palgrave.jors.2600350).

Mehregan, M. R., Hosseinzadeh, M., and Kazemi, A. 2012. "An application of Soft System Methodology". Procedia - Social and Behavioral Sciences (41), pp. 426-433 (doi: 10.1016/j.sbspro.2012.04.051).

Mingers, J., and Sarah, T. 1992. "The use of soft systems methodology in practice". Journal of the Operational Research Society (43:4), pp. 321-332 (doi: 10.2307/2583155).

Okes, D. 2019. Root cause analysis: the core of problem-solving and corrective action, Second Edition. Milwaukee, USA: ASQ Quality Press.

Por, J. 2008. "The use of soft system methodology (SSM) in a serviced-focussed study on the personal tutor's role". Nurse Education in Practice (8:5), pp. 335-342 (doi: 10.1016/j.nepr.2007.12.002).

Rodriguez, J. 2016. "Step 6: part I-root cause analysis," in CAPA in the Pharmaceutical and Biotech Industries, First Edition. Cambridge, UK: Woodhead Publishing - Elsevier.

Ulloa, R. R., and Careces, A. P. 2005. "Soft System Dynamics Methodology (SSDM): Combining Soft Systems Methodology (SSM) and System Dynamics (SD)". Systemic Practice and Action Research (18), pp. 303-334.

Wheeler, F. P. 2000. "Reviewed Work: Systems Thinking, Systems Practice: Includes a 30-Year Retrospective by P. Checkland". The Journal of the Operational Research Society (51:5), pp. 1158.

Zahedi, F. 1987. "Reliability of Information Systems Based on the Critical Success Factors Formulation”. MIS Quarterly (11:2), pp. 187-203.

\section{How to cite:}

Putri, T. S., Tolle, H., and Aknuranda, I. 2021. "Information Management and Information System Analysis to Support the Achievement of University Performance Agreements with the Government," Jurnal Sistem Informasi (Journal of Information System) (17:1), pp. 30-43. 